$\mathbb{T}$ periodica polytechnica

Civil Engineering

$55 / 1(2011) 3138$

doi: 10.3311/pp.ci.2011-1.04

web: http://www.pp.bme.hu/ci

(c) Periodica Polytechnica 2011

RESEARCH ARTICLE

\section{On site mechanical characterization of the ballast state}

\author{
Pierre Breul / Gilles Saussine
}

Received 2010-09-28, revised 2010-11-29, accepted 2010-12-08

\begin{abstract}
Ballast is a major railway component whose behaviour is still not sufficiently controlled. The identification of mechanisms leading to track ageing is difficult to achieve as the process occurs over several years at particle scale. Models have been proposed to take into account ballast characteristics and provide a description of geometrical and structural modifications of ballast particles through time. To be relevant, these models must be supplied with reliable and realistic input data such as on-site density and stiffness modulus. This article presents results that could provide these parameters, starting with on-site tests that link them with cone penetration energy.
\end{abstract}

\section{Keywords}

ballast - on site characterization - penetration test - density . stiffness

\section{Pierre Breul}

LaMI, Blaise Pascal University, Clermont-Ferrand, France,Polytech'Clermont département de Génie Civil Campus des cézeaux, BP 20663174 AUBIERE cedex, France

e-mail: pierre.breul@polytech.univ-bpclermont.fr

\section{Gilles Saussine}

Direction de l'Innovation et de la Recherche, 45 rue de Londres 75379 Paris Cedex 08, France

e-mail: gilles.saussine@sncf.fr

\section{Context and purposes}

Ballast is an important railway component whose behaviour is still not sufficiently controlled. Identifying the mechanisms leading to track ageing is difficult since the process occurs over several years at particle scale. Periodic monitoring of railway track provides indications on track geometry and allows identifying defects [14, 16, 28]. However, these data do not allow diagnosing ballast state.

Several experimental and numerical studies have been carried out in order to better understand track behaviour and study the problems related to relative settlement or carry out maintenance.

These experimental studies were carried out to better understand railway settlement under cyclic stress and characterize ballast behaviour. By using a test bench with ballast at $1 / 3$ scale, Bodin and Guerin [6, 13] proposed settlement laws while Al Shaer [3] highlighted ballast fluidification for certain stresses. Lim [17, 18] and Indraratna [14] characterized ballast degradation and proposed indicators to qualify the degree of ballast pollution.

Numerical studies have highlighted that continuous modelling of the ballast was perfectible. Indeed ballast under sleepers is in a confined environment, thus in a configuration that makes it difficult to reproduce its behaviour by using traditional experimental methods (e.g. triaxial tests).

Models have been proposed to take into account ballast characteristics and used to analyze the lateral resistance of a "new" ballast and its behaviour under loading cycles and during tamping [10, 17, 22, 25]. These models based on the discrete elements method provide a description of geometrical and structural modifications of ballast particles through time. To be relevant, these models require reliable and realistic input data and must be validated by site investigations.

Among the input parameters necessary for supplying the numerical models the main ones are on-site density, stiffness modulus, geometry and the arrangement of the medium. The goal of this study is to be able to link the ballast's mechanical characteristics at various stages of its life (after deposit, after tamping, after $\mathrm{X}$ loadings and at end of lifetime), by using measurements obtained from on-site tests. 


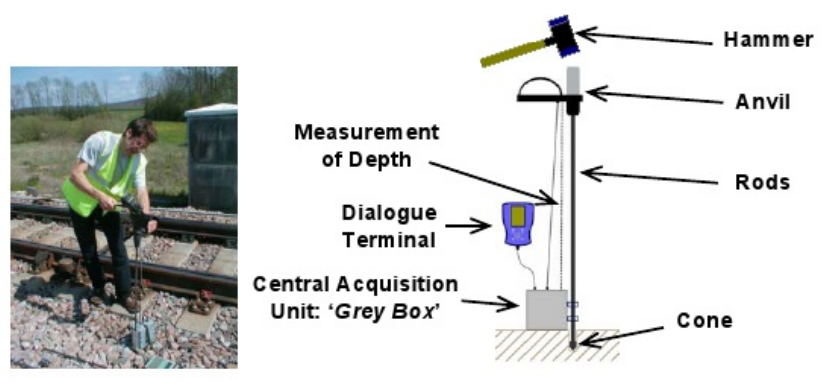

Fig. 1. Use of the panda on a track and principle of the device

Panda is a light dynamic penetration test developed several years ago [11, 12, 30] at the Laboratory of Civil Engineering of Blaise Pascal University - Clermont-Ferrand. Panda is a manual penetrometer using variable energy. Its principle consists in driving a cone (cone area is 2 or $4 \mathrm{~cm}^{2}$ ) into the soil with the help of a set of $14 \mathrm{~mm}$ rods by blowing a standardized hammer on the head of the device. For each blow, the energy of the impact is computed and the driving depth of the cone is recorded. The masses being know, by using the Dutch formula (pile-driving formula) [20], the device provides on site the cone penetration energy measurement of the material crossed as a function of depth. One of its main advantages is that it allows carrying out tests within a short time without interrupting railway traffic (Fig. 1).

As it can be seen in Fig. 2, the cone penetration energy obtained in the ballast with Panda shows significant variations, as a function of the place where the test is carried out on the track (between sleepers, under the sleeper, between rails). Moreover, good repeatability is observed for cone penetration energy in tests performed at the same place on the track. The results tend to show that cone penetration energy is linked to the on-site mechanical state of the ballast.

The aim of this work is to obtain ballast macroscopic characteristics by carrying out cone penetration energy measurements. The first part of this paper describes the experimental study realised in order to establish a relation between material density and cone penetration energy obtained by Panda after which the second part presents a study of ballast modulus variation (vertical stiffness modulus) according to density. The results obtained show that it is possible to link ballast modulus to the on site cone penetration energy obtained by Panda.

\section{Relation between ballast density and cone penetra- tion energy}

Previous works have shown [8, $, 9,24,26]$ that for a given material and a defined water content, the on-site density of granular materials could be estimated with good precision by cone penetration energy. This parameter is all the more interesting as a low variation of density involves a high variation of penetration resistance. This is the relation for the ballast that the experimental works presented in the next section attempt to highlight.

\subsection{Experimental procedure and tests}

The experimental procedure developed consisted in studying the average variations of resistance obtained in a ballast placed in a mould (calibration chamber) for different states of density. A cylindrical mould, $38 \mathrm{~cm}$ diameter and $80 \mathrm{~cm}$ height, was used (Fig. 3). The size of the calibration chamber has been chosen in order to avoid edge effects on the cone resistance values and to observe and exceed the critical depth appearing during a penetration test. Indeed, Salgado et al. [?28] showed in a large study concerning tests in calibration chamber, that the static penetration was sensitive to the side effects of the chamber until values of the ratio $\mathrm{D} / \mathrm{d}$ (D calibration chamber diameter, $\mathrm{d}$ : cone diameter) being able to reach 120, even 150. Van der Berg [29], Lunne et al. [19], Chaigneau [7], Ahmadi et Robertson [1, 2] confirmed this observation and showed this sensibility is all the more important as the relative density and the confining pressure are important. Concerning the Panda penetrometer, Chaigneau [7] (experimentally) and then Benz [5] (numerically) showed that the effect can be neglected for a ratio $\mathrm{D} / \mathrm{d}>30$ (in our case the ratio $\mathrm{D} / \mathrm{d}$ is about 24 due to the size of the ballast particle). These results have been confirm by Ahmadi [2] and Iqbal [15] who propose a ratio $\mathrm{D} / \mathrm{d}>40$. For a $16 \mathrm{~mm}$ cone diameter and for coarse soils with an important friction angle $\left(\phi=45^{\circ}\right)$ models advocate to have a $18 \mathrm{~cm}$ radius area around the cone and a $80 \mathrm{~cm}$ height.

The ballast used for the tests was a new ballast of basaltic origin, having the characteristics defined by standards NF EN 13450 [21] and a particle size distribution of $25-50 \mathrm{~mm}$.

The ballast was set up according to various modes (pluviation, staking, vibration, ramming) in the mould to obtain densities varying between 1.4 (loose state) and 1.7 (very compact state), in thin layers to obtain good homogeneity.

In order to ensure that the properties of the ballast were not modified and ensure that the ballast studied conformed to the criteria of standard NF EN 13450 [21], a ballast particle size analysis was performed after carrying out each series of tests. This analysis was carried out to ensure that no significant amount of fine particles had been formed during the set up and the tests. The maximum fine content value obtained in all the tested moulds was about $2 \%$.

3 light penetration tests (Panda test) (Fig. 2) were carried out for each of the 21 moulds constituted. A total of 63 tests were performed. The results obtained show a good agreement between the cone resistance values measured in the calibration chamber and those measured on site.

Several studies have shown [12], that in a granular medium of homogenous density and water content, penetration energy becomes quasi-constant from a certain depth called "critical depth". In our study critical depth was estimated at $15 \mathrm{~cm}$ on average for all the drillings. Analysis of cone penetration energy was carried out using the data obtained below this critical depth. 

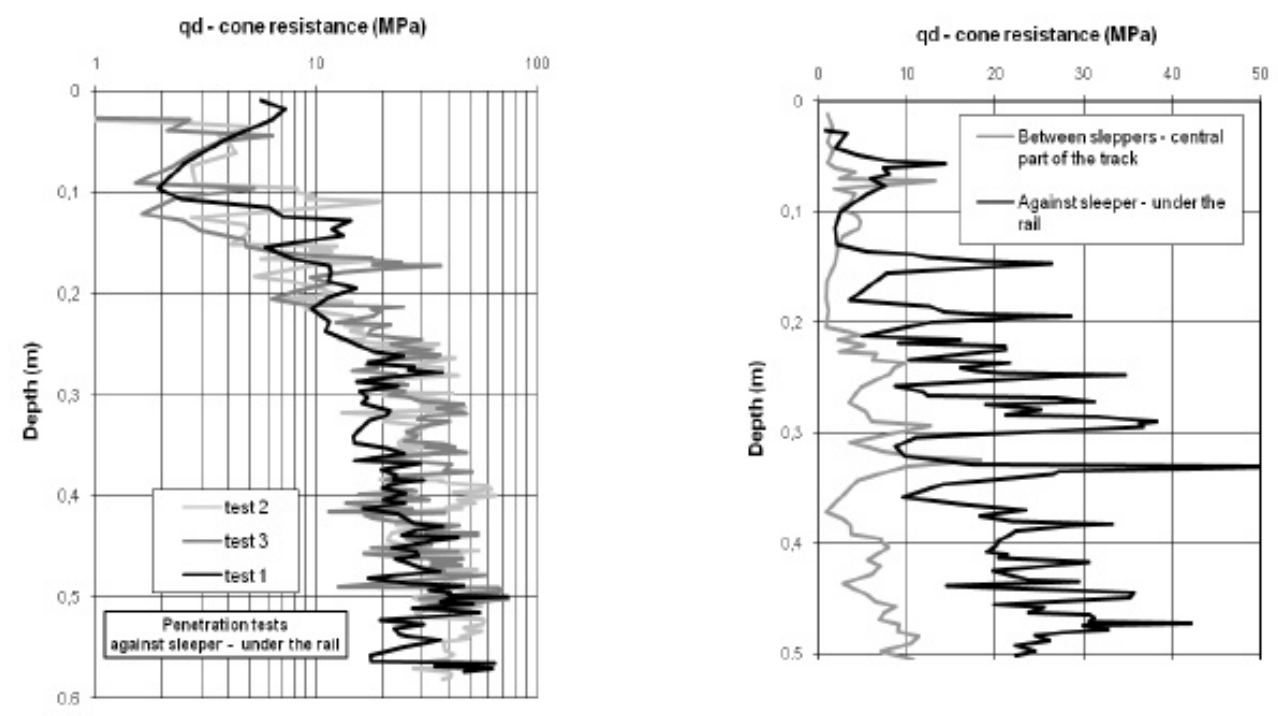

Fig. 2. On site penetrometric Panda tests performed in the ballast at different track areas

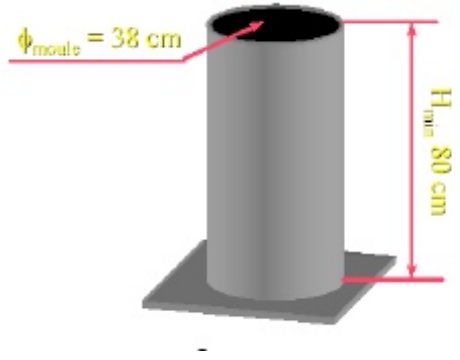

a)

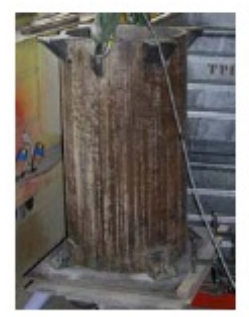

1.

b)

Fig. 3. a) Characteristics of the calibration chamber. b) Calibration chamber and panda tests in the mould.

As the Panda dynamic penetration test is performed using a manual penetrometer, the beating energy applied to the ground is not constant. Moreover, cone penetration for the same beating energy varies according to soil resistance. Thus measurements of cone penetration energy in the ballast are not uniformly distributed over depth. This is the reason why the application of statistical processing to the raw penetration results obtained does not give the same "statistical weight" to each measurement. In order to eliminate this problem, the raw signal was subjected to regulation for each test [7]. This regulation (Eq. (1)) was performed according to a regulation step equal to the average cone penetration measured under the critical depth.

$$
q_{d R E G}=\frac{\sum\left(q_{d i} \cdot e_{i}\right)}{\sum e_{i}}
$$

with: $q_{d R E G}$ : regulated cone penetration energy (MPa)

$q_{d i}$ cone penetration energy at point of depth $\mathrm{Z}(\mathrm{MPa})$

$e_{i}$ cone penetration obtained for a value of c penetration energy at point of depth $\mathrm{Z}(\mathrm{m})$

\subsection{Results and analyses}

All the Panda tests carried out are grouped in Fig. 4 which shows the overall progression of average cone penetration energy calculated under the critical depth according to ballast density or unit weight in the mould. Fig. 4 shows three tendency curves calculated according to the order of the Panda tests in each mould. The tendency curve shapes are similar to those found in other studies on granular materials [7].

The results analysis clearly shows the influence of the Panda test order on the characteristics measured. Indeed, the value of the points representing the "first test" is generally higher than those of the points representing tests $n^{\circ} 2$ and 3 .

This influence is especially obvious for high densities which can be explained by the fact that the first test performed created a cavity which, during the following tests, led to structural deformation, easier rearrangement of the granular medium and consequently the application of lower penetration energy. On the other hand, for low densities, the state of compaction is less significant and the first Panda test had less influence on the structure of the global granular medium. This was due to the fact that there were enough voids to allow local particle reorganization. The penetration energy between the 3 tests in the same mould was thus more homogeneous.

According to these observations, it was not necessary to take into account the results obtained from the third penetrometric test in the same mould.

From the results obtained with the first set of tests, it is possible to propose a relation between unit weight or density and cone penetration energy. Based on several studies [4, 8, 9, 19, 23, 24] 


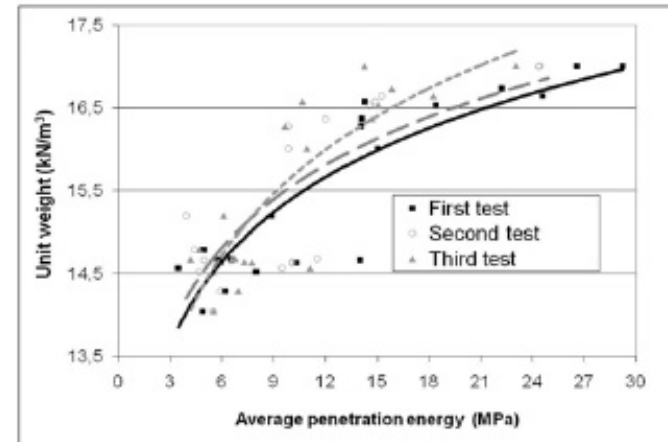

a)

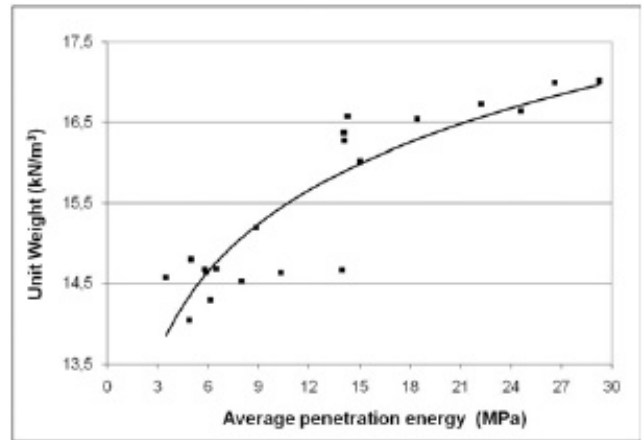

b)
Fig. 4. Evolution of average cone resistance (measured under the critical depth) according to the unit weight of the ballast and: a) to the number of the showing a good agreement of the logarithmic relation between density and cone resistance for soils, the relation proposed is as follows:

$$
\gamma_{d}=148.8 \ln \left(q_{d}\right)+1194.8
$$

Where: $\gamma_{d}$ dry unit weight $\left(\mathrm{kN} . \mathrm{m}^{-3}\right)$

$q_{d}$ cone resistance $(\mathrm{MPa})$

This relation is valid for $q_{d}>1 \mathrm{MPa}$ and is of course applicable to ballast whose grading curve meets the same specifications of standard particle size distribution and mineralogy as that of the ballast tested here. Nevertheless, mineralogical characteristics would have little influence on this relation because the selection criteria for the ballast are relatively strict in terms of the size, shape and hardness of its elements.

The variability obtained for low density values can be explained in particular by the size of the elements of the medium analyzed in comparison to the cone size of the light dynamic penetrometer, by the sample size and by the state of compaction of the granular media facilitating its rearrangement. However, as can be seen in Fig. 4 this variability is notably reduced for higher densities.

To conclude on these tests, it thus seems possible to link cone penetration energy and ballast density. This relation will therefore allow the assessment of the on-site density. Given the problems of representative elementary volume and variability within the medium, a sufficient number of tests will be necessary to obtain a reliable estimation of this parameter.

\section{Relation between ballast density and oedometric modulus}

In order to link on site measurements with the model input parameters, i.e. the modulus, we tried to establish a relation between ballast density and the oedometric modulus.

\subsection{Experimental procedure and tests}

A set of tests was carried out in order to link ballast density to a vertical rigidity modulus and to cone penetration energy. Oedometric loading tests (Fig. 5) were performed on samples of 20 and $40 \mathrm{~cm}$ thickness. Loading was applied by a gantry equipped panda test in the calibration chamber, b) for the first set of test.

with a 100 ton jack and by a circular loading plate of $80 \mathrm{~kg}$ and with the same diameter as that of the internal mould $(38 \mathrm{~cm})$. Vertical displacements were measured by 3 sensors arranged on the loading plate. A loading sensor with a capacity of 200 tons measured the loading intensity on the ballast. Tab. 1 1 summarizes the characteristics of the tests carried out. The tests were carried out with the same ballast used for the tests presented previously. On the whole, 4 tests were carried out with 2 different states of initial density: one loose state with an initial density around 1.4 and one fairly dense state of initial density around 1.5.

During the test, loading and unloading cycles were carried out with a loading rate of $70 \mathrm{~mm} /$ minute. After each test, the ballast particles were all sorted to eliminate damaged particles and those whose size was lower than $25 \mathrm{~mm}$. Thus the mass proportion of particles less than $25 \mathrm{~mm}$ (D25) was determined and an evaluation of the proportion of fine particles was performed to judge ballast cleanness and homogeneity (Tab. 11).

\subsection{Results and comments}

Fig. 6 provides for each test the evolution of the void ratio (calculated on the basis of average displacement recorded by the 3 sensors) according to the pressure applied. It should be noted that the initial void ratios are questionable due to the test starting conditions (loading plate balanced on only a few particles).

Fig. 7 shows the stress-strain curve. After the first unloading, all the curves show 2 distinct parts where behaviour is quasilinear. The first part of the curve corresponds to the quasi-elastic area with a majority of reversible deformations. The second part of the curve corresponds to the plastic deformation area.

From these loading curves, 2 moduli were calculated for each cycle: an elastic modulus (calculated in the quasi-elastic deformation area) and a deformation or hardening modulus (Eecr) in the second part of the curve. The hardening modulus was calculated as the tangent modulus to the slope of the loading curve in the plastic deformation area. Concerning the elastic modulus, of the different calculation options (unloading tangent modulus, unloading secant modulus, initial tangent modulus of loading, loading secant modulus, etc.) we decided to measure the load- 

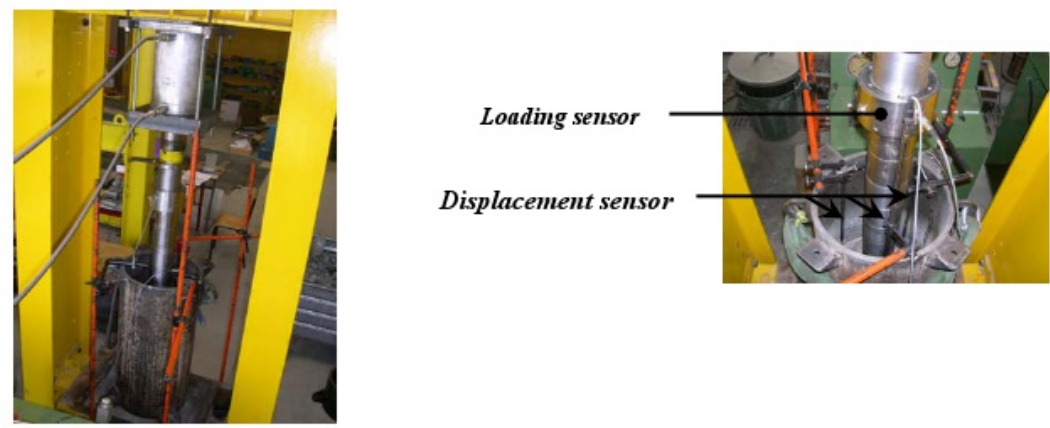

Fig. 5. Oedometric loading test

Tab. 1. Initial and final characteristics of the ballast for each oedometric loading test

\begin{tabular}{ccccccc}
\hline & Ballast layer thickness $(\mathrm{cm})$ & Initial density & Initial void ratio & Final density & Final void ratio & $\begin{array}{c}\text { Mass proportion of particles } \\
\text { lower than 25 mm (D25) } \\
\text { at the end of the test (\%) }\end{array}$ \\
\hline Test 1 & 20 & 1,37 & 0.93 & 1,43 & 0.85 & 1,20 \\
\hline Test 2 & 20 & 1,51 & 0.75 & 1,58 & 0.68 & 3,16 \\
\hline Test 3 & 40 & 1,42 & 0.87 & 1,47 & 0.80 & 2,08 \\
\hline Test 4 & 40 & 1,57 & 0.69 & 1,62 & 0.63 & 2,05 \\
\hline
\end{tabular}

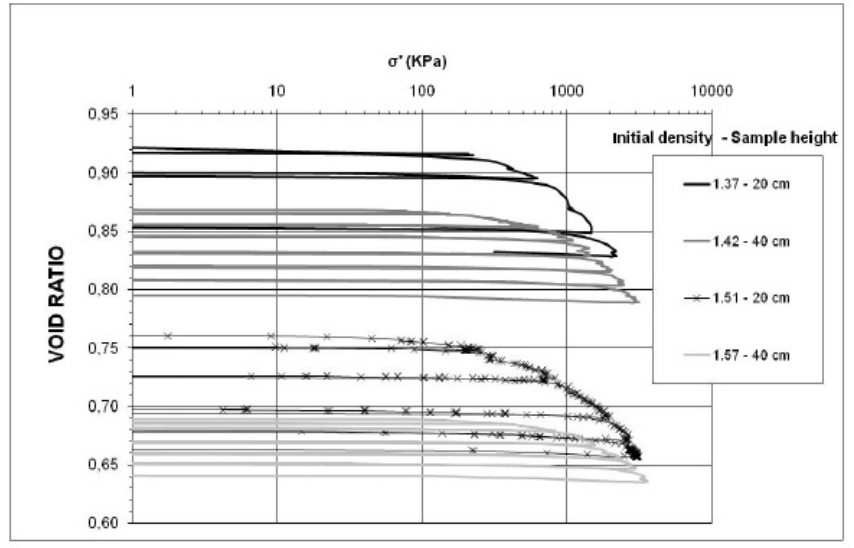

Fig. 6. Evolution of the void ratio according to the pressure applied for 4 different initial densities

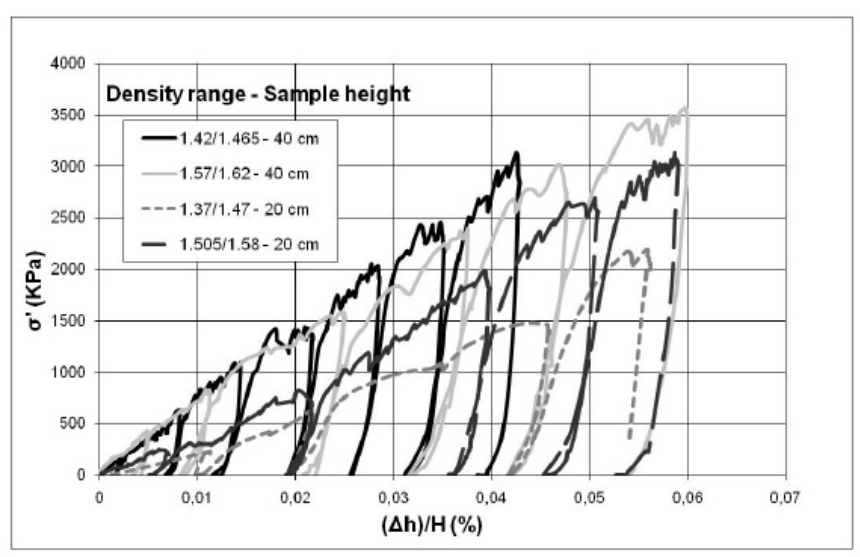

Fig. 7. Stress-strain curve for the different tests

ing secant modulus (Esec) calculated between a loading stress of $100 \mathrm{kPa}$ (beginning of the loading) and the stress corresponding to the maximum stress before the previous unloading. (Fig. 8).

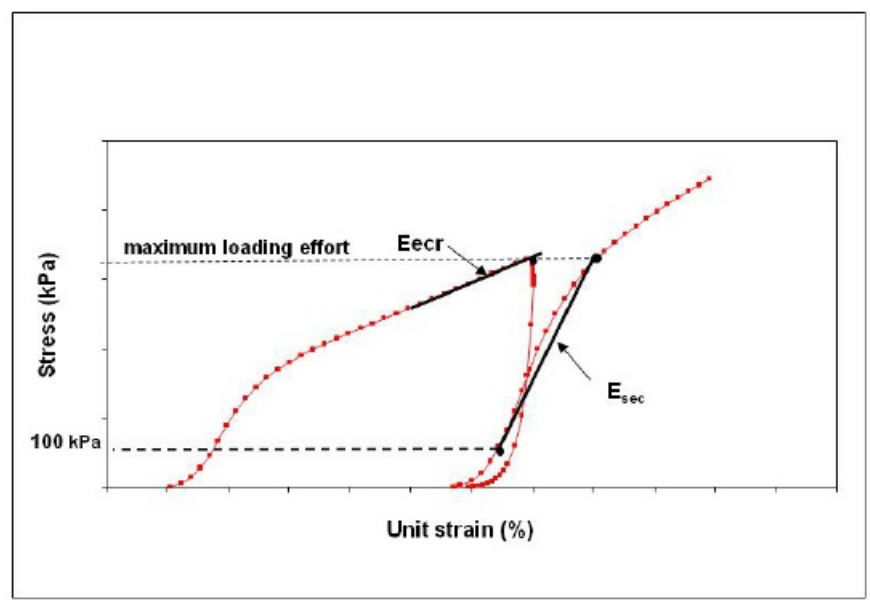

Fig. 8. Moduli computation

The loading secant elastic modulus was chosen because of the experimental conditions. During unloading the speed was not under control and only a low number of data were recorded; also the beginning of the loading curve was difficult to establish for the same reasons.

By using the loading curves, it was possible to calculate compression index $\mathrm{Cc}$ as well as the oedometric modulus for each loading cycle according to following expressions':

$$
C c=-\frac{\Delta e}{\Delta \log \sigma}=\frac{e 1-e 2}{\log \sigma 2-\log \sigma 1}
$$

$$
E_{\text {oed }}=-\frac{\Delta \sigma}{\Delta e}\left(1+e_{1}\right)=\frac{\sigma_{2}-\sigma_{1}}{e_{1}-e_{2}}\left(1+e_{1}\right)
$$

With: $C c$ : compression index 
$E_{\text {oed }} / E$ : oedométric / elastic modulus (MPa)

$e_{i}:$ void ratio

$\sigma_{i}:$ stress (MPa)

The values of these parameters provided in Tab. 2 correspond to the values obtained during the last loading cycle.

Under the linear elasticity of Hook's hypothesis, the Young modulus can be deduced from the oedometric modulus by the following expression:

$$
E=E_{\text {oed }} \frac{(1+v)(1-2 v)}{(1-v)}
$$

With $v=0,3$ (Poisson coefficient)

The comparison between our results and those obtained by Lim [17] shows good agreement concerning the order of magnitude for the values of $\mathrm{Cc}$ at equivalent densities.

The evolution of the loading secant and hardening oedometric moduli according to the initial ballast density for each loading cycle is provided in Figs. 9 and 10 . The analysis of these results highlights a little densification of the ballast during loading cycles whatever the initial density in the mould. Secondly, it can be noted that the secant moduli evolution is quite similar for each density state and tends to an asymptotic value. The modulus initial values are similar and relatively low for each initial density but these values have a quick evolution in the first loading cycles before stabilizing. The evolution is as faster as the initial density is important. Indeed, due to the boundary conditions and to the loading way (oedometric loading), it makes possible to set up the loading arches very quickly without material structure rearrangement between each cycle.

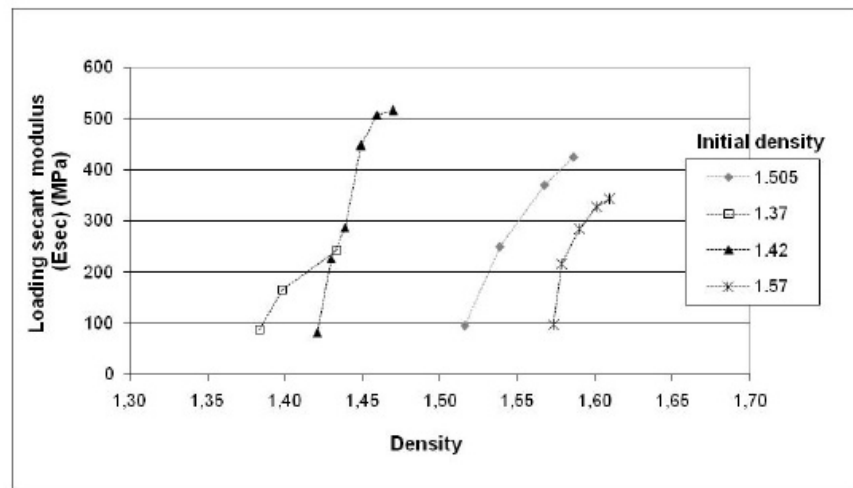

Fig. 9. Variation of the loading secant modulus (Esec) for each loading cycle according to the initial density of the sample

Concerning the hardening modulus, the results show a relative stability (around 60 to $75 \mathrm{MPa}$ ) of this modulus whatever the sample density. It can be all the same noted a slight increasing with the density.

The maximum vertical pressures applied were about 2 to 3 $\mathrm{MPa}$ and the range of the elastic modulus values is between 180 and $400 \mathrm{MPa}$. These values are equivalent to those given in the literature for compacted sand gravel.

According to our tests, it appears that the maximum on-site densities reached for ballast without particle destruction are

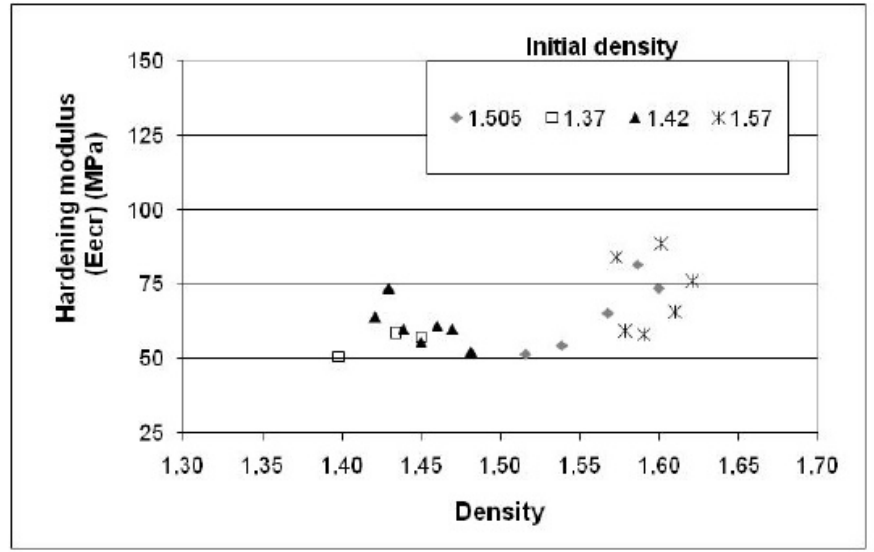

Fig. 10. Variation of the hardening modulus (Eecr) for each loading cycle according to the initial density of the sample

about 1.7 to 1.8 (void ratio between 0.6 and 0.5 ). For the 4 tests carried out, the percentage of elements passing through the $25 \mathrm{~mm}$ sieve does not exceed $3 \%$, which is lower than the limits fixed by the standards for clean ballast.

Our results show that the modulus of ballast seems weakly influenced by its initial density but rather by the number of loading cycles. The modulus values are relatively low at the start of loading but quickly reach high and asymptotic value after certain cycles. Concerning the values obtained, it has to keep in mind that for high densities, oedometric conditions influence the modulus values by over-estimating them. Finally, in view of these results, it appears difficult to obtain the ballast stiffness from a penetration test. Indeed, due to the oedometric conditions, the asymptotic elastic stiffness is not correlated to the density. The comparison of on site plate modulus with the cone resistance and the density could maybe provide a better relation. The initial ballast density influences on the other hand the evolution of the ballast concerning settlements and attrition. Using the cone resistance to evaluate this density in situ could improve the assessment of the railway track. Moreover due to the easy implementation of the Panda device, it is possible to realize tests on all the part of the track (even under the sleeper).

\section{Conclusions and outlook}

This article proposed an experimental methodology based on the use of a light dynamic penetrometer to perform the on site characterization of ballast state. It has been shown that it was possible to establish a relation linking cone resistance or the energy necessary for cone penetration in this material with on site density. Due to the size of the particles and to the ballast behaviour, results show some variability. In order to obtain a more reliable relation an important number of tests would be necessary. The development of a numerical model of the penetration test in the calibration chamber will provide a solution to improve this relation.

Concerning the evaluation of the modulus, it has been shown that it was weakly influenced by its initial ballast density but rather by the number of loading cycles. It seems that the moduli 
Tab. 2. Characteristics obtained for each test during the last cycle of loading

\begin{tabular}{ccccccc}
\hline & $\begin{array}{c}\text { Ballast layer } \\
\text { thickness }(\mathrm{cm})\end{array}$ & Initial density & Final density & $\begin{array}{c}\text { Compression index } \\
C c\end{array}$ & $\begin{array}{c}\text { Secant modulus Esec (Mpa) } \\
\text { (measured on the last loading) }\end{array}$ & $\begin{array}{c}\text { Young modulus (Mpa) } \\
\text { (measured on the last loading) }\end{array}$ \\
\hline Test 1 & 20 & 1,37 & 1,43 & 0.27 & 243 & 180 \\
\hline Test 2 & 20 & 1,51 & 1,58 & 0.29 & 424 & 315 \\
\hline Test 3 & 40 & 1,42 & 1,47 & 0.18 & 515 & 382 \\
\hline Test 4 & 40 & 1,57 & 1,62 & 0.39 & 342 & 254 \\
\hline
\end{tabular}

quickly reach asymptotic value.

The results obtained seem to be in agreement with the real state of the material in place and with results of the literature and will make it possible to better specify the input parameters of numerical models.

Lastly, in order to obtain finer characterization and develop realistic and usable numerical models, knowledge of spatial and temporal variability will be necessary. However, the facility of application of the techniques proposed should make this possible.

Although the mechanical study makes it possible to obtain a certain number of elements that improve the data supplying calculation models, it fails to obtain information on the structure of the medium. However the behaviour and response to a given stress depend on the structural state of the medium. This is why we are now developing an on-site tool in order to evaluate void ratio and the orientation of contacts between particles.

\section{References}

1 Ahmadi M M, Robertson P K, Calibration chamber size and boundary effetcs for CPT qc measurements, Proceedings of 2nd International Conference on Site Characterisation, ISC 02 (Portugal, September 19, 2004), pp. 829834.

2 _ A numerical study of chamber size and boundary effects on CPT tip resistance (qc) in sand, Scientia Iranica 15 (2008), no. 5, 541-553.

3 Al Shaer A, Duhamel D, Sab Â K, Foret Â G, Schmitt Â L, Experimental settlement and dynamic behavior of a portion of ballasted railway track under high speed trains, Journal of Sound and Vibration 316 (2005), no. 1-5, 211-233.

4 Arquié G, Morel G, Le compactage, Ed. Eyrolles, Paris, 1988.

5 Benz M A, Mesures dynamiques lors du battage du pénétromètre Panda 2 , $\mathrm{PhD}$ thesis, Blaise Pascal University, Clermont Ferrand, France, 2009.

6 Bodin-Bourgoin V, Tamagny P, Sab Â K, Gautier P É, Détermination expérimentale d'une loi de tassement du ballast des voies ferrées soumises à un chargement latéral, Canadian Geotechnical Journal 43 (14) (2006), no. 10, 1028-1041.

7 Chaigneau L, Caractérisation des sols de surface a l'aide d'un pénétromètre, $\mathrm{PhD}$ thesis, Blaise Pascal University, Clermont Ferrand, France, 2001.

8 Chaigneau L, Bacconnet C, Gourvès R, Penetration test coupled withgeotechnical classification for compacting control, Proceedings of International Conference on Geotechnical \& Geological Engineering, GeoEng2000 (Melbourne, Australia, November 19, 2000).

9 Chaigneau L, Gourvès R, Boissier D, Compaction control with a dynamic cone penetrometer, International Workshop on Compaction of Soils, Granulates and Powders (Innsbruck, Austria, February 28, 2000).
10 Cholet C, Saussine G, Gautier P E, Dubois F, Bohatier C, Combe G, Sab K, Application of discrete element methods to the modelling of ballasted track, World Congress on Railway Research (WCRR ) (Edimbourg, Scotland, 2003).

11 Gourves R, Barjot R, The Panda ultralight dynamic penetrometer, Proceedings of 11th European Conference on Soil Mechanics and Foundation Engineering, Danish Geotechnical Society (Copenhagen, Denmark, 1995/05/19), pp. 83-88.

12 Gourves R, Oudjehane F, Zhou S, The in Situ Characterization of the Mechanical Properties of Granular Media with the Help of Penetrometer, proceedings of 3rd International Conference on Micromechanics of Granular Media, Powders and Grains (Duram, USA, 1997), pp. 57-60.

13 Guerin N, Approche expérimentale et numérique du comportement du ballast des voies ferrées, $\mathrm{PhD}$ thesis, Ecole nationale des ponts et chaussées, Université de Paris XII, Paris, France, 1996.

14 Indraratna D, Salim W, Deformation and degradation mechanics of recycled ballast stabilised with geosynthetics, Soils and Foundations 43 (2003), no. 4, 35-46.

15 Iqbal M S, Discrete element modelling of cone penetration testing in coarse grain soils, Master's thesis, University of Alberta, USA, 2004.

16 Krakutovski Z, Etude de la dégradation géométrique des voies ferrées, Master's thesis, Ecole Nationale des Ponts et Chaussées, Université de Paris XII, Paris, France, 2000.

17 Lim W L, McDowell G R, Collop A C, The application of Weibull statistics to the strength of railway ballast, Granular Matter 6 (2004), no. 4, 229-237.

18 Lim W L, McDowell G R, Discrete element modelling of railway ballast, Granular Matter 7 (2005), no. 1, 19-29.

19 Lunne T, Robertson P K, Powell J J M, Cone Penetration Testing in Geotechnical Practice, Blackie Academic, Chapman Hall Publishers, London, UK, 1997.

20 Mahler A, Szendefy J, Use of cone penetration test in pile design, Periodica Polytechnica Civil Engineering 47 (2003), no. 2, 101-106.

21 NF EN 13450., Granulats pour ballast des voies ferrées, European Standard, 1996.

22 Oviedo-Marlot X, Etude du comportement du ballast par un modèle micromécanique (application aux opérations de maintenance de la voie ferrée ballastée), PhD thesis, Université de Paris XII, Paris, France, 2001.

23 Quibel A, Contrôle de compactage des remblais au moyen du pénétrodensitographe LPC le PDG 1000, Rapport des laboratoires, Rouen, France, 1989.

24 Rahim A, Prasad S N, George K P, Dynamic Cone Penetration Resistance of Soils-Theory and Evaluation, Proceedings of the Geo-Trans Conference (Los Angeles, USA, 2004), pp. 1755-1766.

25 Saussine G, Cholet C, Gautier P E, Dubois F, Bohatier C, Moreau J $\mathbf{J}$, Modelling ballast behaviour under dynamic loading. Part 1: A $2 D$ polygonal discrete element method approach, Computation Methods in Applied Mechanics and Engineering 195 (2006), no. 19-22, 2841-2859.

26 Salgado R, Mitchell J K, Jamiolkowski M, Cavity expansion and penetration resistance in sand, Journal of Geotechnical and Geoenvironmental Engineering 123 (1997), no. 4, 344-354.

27 _ Calibration Chamber Size Effects on Penetration Resistance in 
Sand, Journal of Geotechnical and Geoenvironmental Engineering 124 (1998), no. 9, 878-888.

28 Selig E T, Waters J, Track and substructure management, Thomas Telford Ltd, London, UK, 1994.

29 Van der Berg P, Analysis of soil penetration, $\mathrm{PhD}$ thesis, Technische Universiteit Delft, Holland, 1994.

30 Zhou S, Caractérisation des sols de surface à l'aide du pénétromètre dynamique léger de type Panda, $\mathrm{PhD}$ thesis, Université Blaise Pascal, Clermont Ferrand, France, 1997. 